\title{
Mathematical model of the standalone electrical supply system with distributed photoelectric generation
}

\author{
Dmitry I. Muravyev ${ }^{1, *}$, Boris V. Lukutin ${ }^{1}$ \\ ${ }^{1}$ National Research Tomsk Polytechnic University, 634050 Tomsk, Russia
}

\begin{abstract}
A promising way to increase the technical and economic characteristics of standalone power supply systems is to incorporate renewable energy installations in their structure. Photoelectric generators based on distributed sources are optimal technologies for the use of renewable energy sources in $0.4 \mathrm{kV}$ low-voltage power grid. The most common option is a hybrid system with photoelectric power stations (PES) incorporated into the local network of the diesel power station (DPS). Photoelectric stations meet all environmental requirements and can make a significant contribution to the electrification of remote settlements, tourist and agricultural field. This paper deals with stabilization of voltage value and reduction of losses of electric energy depending on the parameters of elements of power supply systems of radial type $(0,4 \mathrm{kV})$ with an installed capacity of up to $100 \mathrm{~kW}$. The research has been conducted by simulating the operating modes of hybrid power systems of various configurations. To analyze the joint work of a photoelectric station with a diesel power station, a mathematical model is created in the Simulink (SimPowerSystems) application of the MatLab R2016b program. Most of the known works do not show the issues of quality and power losses in the standalone power supply system with photoelectric distributed generation. $[5,6,7,9,10]$.
\end{abstract}

\section{Object of research}

A standalone system of power supply of a radial type with a voltage of $0.4 \mathrm{kV}$, which is characteristic for electrification of small settlements, was considered. The researches were carried out for the geographic conditions of the middle latitudes of the territory of the Russian Far East.

\section{Research objectives}

Creation of a working model of a standalone power supply system with distributed photoelectric generation, which takes into account the need for a large number of calculations associated with daily changes in insolation and power consumption. In

\footnotetext{
Corresponding author: dim15@,tpu.ru
} 
particular, the stability of the magnitude of voltage and losses in transmission lines is of interest, depending on the ratio of the power of the DPS and PES, the points of connection of photoelectric stations to the autonomous electric network [4].

\section{Results of the research}

To analyze the hybrid operation of a photoelectric power station with a diesel power station, a mathematical model is created for the load in the Simulink application of the MatLab R2016b program, shown in Fig. 1. SimPowerSystems library was used for simulation of transient processes. The PES model is based on the approximated characteristics of the photoelectric generator and simplified mathematical functions [8].

The length of power transmission lines is limited by the maximum allowable voltage deviation at the load at the end of the line relative to the nominal value. The state standard establishes the maximum value of this deviation not more than $10 \%$. Block subsystem "Power function from two parameters" describes the analytical expression of the influence of the ambient temperature and the magnitude of the intensity of solar radiation, with the arrangement of the photo panel perpendicular to the incident rays. $[8,9,10]$.

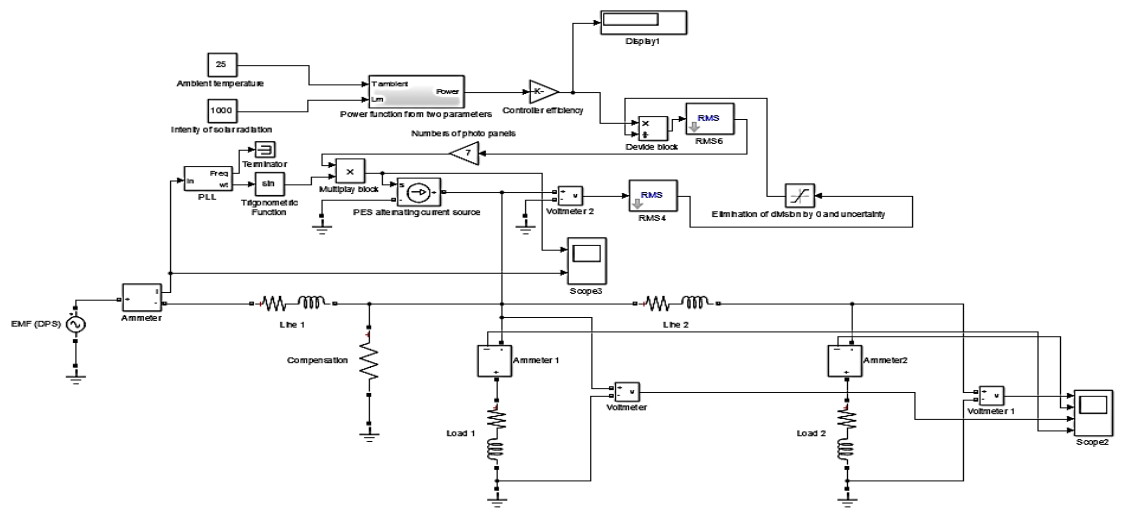

Fig.1. Mathematical model of a standalone power supply system with distributed photoelectric generation.

The equation of the solar power generation function according to the parameters of the ambient temperature and solar radiation intensity [1]:

$$
\left(I_{S C} \cdot U_{O C} \cdot(1+(\alpha-\beta)) \cdot\left(T_{E}-T_{0}\right)\right) \cdot \lambda .
$$

where $I_{S C}$ - short-circuit current of the solar module, A; $U_{O C}$ - open-circuit voltage of the solar module $\mathrm{V} ; \alpha, \beta$ - corresponding temperature coefficients; $T_{E}$ - ambient temperature; $T_{0}$ is the temperature taken as the basis $\left(20{ }^{\circ} \mathrm{C}\right) ; \lambda$ - is the intensity of solar radiation.

In the nominal mode of operation of the DPS, the voltage at the end of the investigated power transmission line model is reduced by $8.04 \%$ relative to the nominal. Connecting an additional source in the form of a photovoltaic station allows to redistribute the load power between the DPS and the PES. As a result, there is a change in the magnitude of the currents in various parts of the transmission line, which reduces the loss of electricity in the wires and provides greater voltage stability in the points of connection of electricity consumers [5].

The obtained data reflect the power consumption by the objects under consideration and the generation of currents in the nodes of the electric grid from the main source of the DPS and the auxiliary PES $[5,9,10]$. 
The results of the simulation showed that the corresponding power of the photoelectric station, depending on the amount of load consumed by the power supply system, makes it possible to reduce the generation of power from the main source of DPS, which entails a reduction in fuel consumption and consumption, diesel segment unloading in summer. With significantly uneven power loads of the power distribution line, it is advisable to connect the power station at the point of connection of the maximum power of the electric consumer [3].

\section{Conclusions}

1. The effectiveness of PES in standalone power supply systems is substantially limited by the conditions of solar insolation and temperature changes. There is a need to use power accumulators.

2. For geographic regions in the mid-latitudes of the north-eastern hemisphere, the large difference in the magnitude of insolation in summer and winter determines the expediency of maximum use of PES in the summer, which contradicts the reduction of summer power consumption.

3. To stabilize the voltage in the power supply system and reduce power losses, it is possible to use the PES closer to the end of the distribution line or to the point of connection of the most powerful consumer [5].

4. This model of a power station with distributed photoelectric generation showed satisfactory simulation results. The model makes it possible to test the investigation of various modes and configurations of hybrid photo-diesel electric power system for the purpose of stabilization and reduction of voltage losses at the investigated time intervals.

\section{References}

1. S.N. Udalov, Renewable energy sources (Publishing House of the National Technical University, Novosibirsk, 2007) [in Russian]

2. B.V. Lukutin, Renewable sources of electricity (Publishing house of Tomsk Polytechnic University, Tomsk, 2008) [in Russian]

3. N.N. Duraev, S.G. Obukhov, I.A. Plotnikov, Izvestiya Tomsk Polytechnic University, 4, 48 (2013) [in Russian]

4. B.V. Lukutin, I.O. Muravlev, I.A. Plotnikov, Power supply systems with wind and solar power plants (Publishing house of Tomsk Polytechnic University, Tomsk, 2015) [in Russian]

5. M.H. Cintuglu, A. Altamirano, O.A. Mohammed, 12th Latin American and Caribbean Conference for Engineering and Technology, (2014)

6. N. Abd Rahim, H. W. Pinga, J. Selvaraja, Procedia Environmental Sciences 17, 537 (2013)

7. J.R. Rodriguez, F. Ruiz, D. Biel, F. Guinjoan, Simulation and analysis of distributed PV generation in a LV network using MATLAB-Simulink// The Spanish Ministry of Science and Innovation through the grants RUE CSD2009-00046, Consolider-Ingenio 2010 Programme, DPI2006-15627-C03-01 and DPI2007-62582.

8. B.V. Lukutin, E.B. Shandarova, A.F. Makarova, I.B. Shvartsman, IOP Conf. Series: Materials Science and Engineering, 127 (2016)

9. J. Wood, Local Energy Distributed generation of heat and power (Published by The Institution of Engineering and Technology, London, 2008)

10. K. Amaresh, V. Sankar. International Journal of Engineering and Innovative Technology, 3 (3), 251 (2013) 